\title{
Design and Development of Smartcoatings for Gas Turbines
}

\author{
I.Gurrappa ${ }^{1}$ and I.V.S. Yashwanth ${ }^{2}$ \\ ${ }^{1}$ Defence Metallurgical Research Laboratory \\ Kanchanbagh PO, Hyderabad-500 058, \\ ${ }^{2}$ M.V.S.R. Engineering College, Nadargul, Hyderabad-501 510, \\ India
}

\section{Introduction}

Development of newer materials / coatings that are multifunctional, smart and possess physical and engineering properties superior to the existing materials / coatings are constantly necessitated for continued technical advances in a variety of fields. In modern times, the design, development, processing and characterization of newer materials / coatings have been greatly aided by novel approaches to materials / coatings design and synthesis that are based on intelligent and unified understanding of the processing structure properties - performance relationships for a wide range of materials / coatings. The ever increasing demands in gas turbines for cost savings as well as restrictions concerning emission of pollutants and noise require steady improvement in engine efficiency, performance, and reliability. The availability of materials / coatings with requisite combination of properties largely dictates performance improvements of the gas turbines. The blades in modern aero, marine and industrial gas turbines are manufactured exclusively from $\mathrm{Ni}$ - based superalloys. A section of a typical gas turbine engine is shown in Fig.1. It is to be noted that hot sections of engine are dominated by Ni- based superalloys. The advanced gas turbine engines need to operate at higher temperatures for obtaining maximum efficiency. The efficiency is directly proportional to operating temperature. Increased temperatures lead to increased high temperature corrosion i.e. oxidation and hot corrosion. High temperature corrosion and in particular hot corrosion (type I and II) is highly detrimental as it causes catastrophic failures if proper materials in association with high performance coatings are not chosen [1-3]. Advances in processing of Ni-based superalloys have allowed evolution of microstructures from equiaxed structures about three decades ago to directionally solidified (DS) multi-grain and single crystal (SC) components today, which enhance temperature capability up to $1250^{\circ} \mathrm{C}$. The majority of $\mathrm{Ni}$ - based superalloy developmental efforts has been directed towards improving the alloy high temperature strength with relatively minor concern being shown to its high temperature corrosion resistance. Further, it is not always possible to achieve both high temperature strength and high temperature corrosion resistance simultaneously because some alloying elements help to improve high temperature corrosion resistance while some may help to improve high temperature strength. It is rare that an alloying element leads to enhancement both in high temperature strength and the high temperature corrosion resistance. This is 


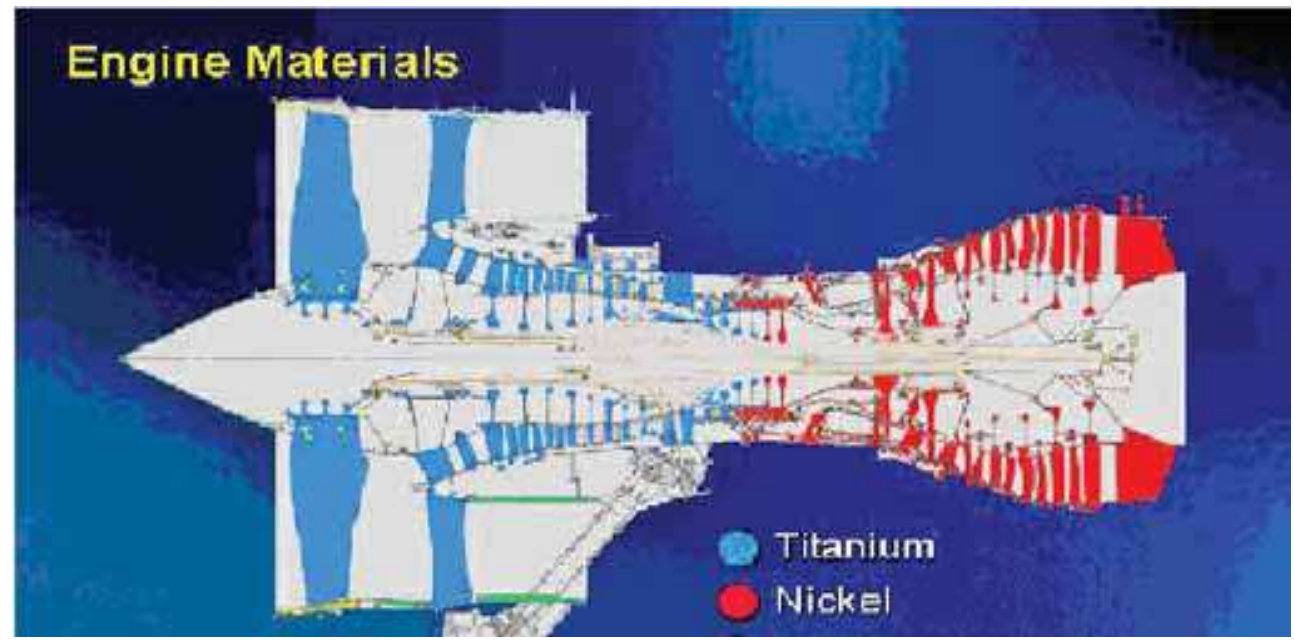

Fig. 1. Significance of nickel based superalloys and titanium based alloys in gas turbine engines

further complicated for marine applications by the aggressivity of the environment, which includes sulphur and sodium from the fuel and various halides contained in seawater. These features are known to drastically reduce the superalloy component life and reliability by consuming the material at an unpredictably rapid rate, thereby reducing the loadcarrying capacity and potentially leading to catastrophic failure of components [1,3]. Thus, the high temperature corrosion resistance of superalloys is as important as their high temperature strength in gas turbine engines [4-7].

\section{Hot corrosion of superalloys}

Fig.2 shows the hot corrosion behavior of few superalloys like Nimonic-75, Nimonic-105, Inconel 718 and $\mathrm{CM} 247 \mathrm{LC}$ corroded in pure $\mathrm{Na}_{2} \mathrm{SO}_{4}$ and $\mathrm{NaCl}$ containing environments at $900^{\circ} \mathrm{C}$. In the presence of pure sodium sulphate, the weight loss was less for all the superalloys [7]. Appreciable corrosion was reported for all the superalloys in the presence of $\mathrm{NaCl}$. It indicates that $\mathrm{NaCl}$ plays a significant role in causing severe corrosion, thereby reducing the superalloy life considerably. Among the superalloys, CM 247 LC was corroded severely indicating that the superalloy is highly susceptible to hot corrosion. In fact many cracks were developed on the scale and subsequently spallation took place for CM 247 LC superalloy. However, there were no cracks and no spallation of oxide scales was reported for other superalloys. In case of CM 247LC alloy, no material was left after exposure of 70 hours to the $\mathrm{NaCl}$ containing environment and only corrosion products with high volume of oxide scales was reported [7]. The appreciable corrosion attack of CM 247 LC superalloy was clearly evidenced by observing large corrosion affected zone (due to appreciable diffusion of corrosive elements present in the environment). Formation of precipitates was further confirmed by EPMA measurements [7]. Sulphur diffusion and formation of metal sulphides preferentially chromium and nickel sulphides was reported to be the influential factor. When sulphide phases are formed in superalloys, Ni- based alloys are inferior to cobalt and iron base alloys, which are especially effective in destroying the corrosion resistance of 

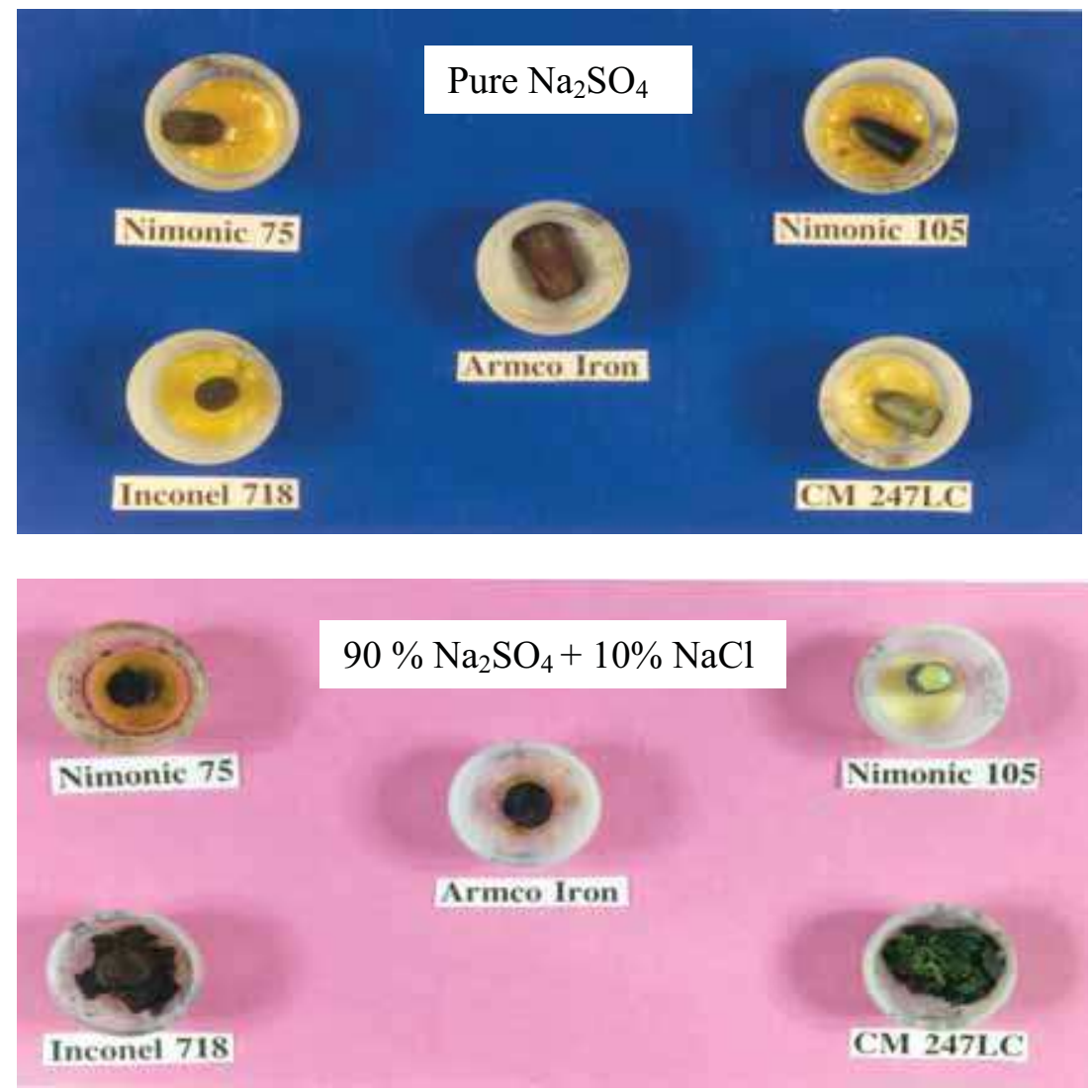

Fig. 2. As hot corroded superalloys at $900^{\circ} \mathrm{C}$ in different environments

alloys [7-8]. It was also reported that the simple Nimonic-75 alloy is more corrosion resistant over complicated CM 247LC because of the presence of small amount of titanium, which helps in forming a protective, adherent and dense chromia layer. Titanium oxide forms beneath the chromia layer and thereby improves the adherence capability of chromia scale [8]. Thus, the alloying elements play a significant role and decide the life of superalloys under hot corrosion conditions [9]. This type of attack greatly reduces the high temperature strength properties and thereby affects the efficiency of the system due to failure of components during service conditions [10].

It is generally accepted that the high temperature capability increases with decreasing $\mathrm{Cr}$ content. Therefore, the chemistry of new superalloys were greatly influenced by reducing $\mathrm{Cr}$ content and increasing rhenium (Re) content with a view to enhance the temperature capability. As a result, the third and $4^{\text {th }}$ generation superalloys contain only 2 to $4 \% \mathrm{Cr}$ but instead contain about $6 \% \mathrm{Re}$, which is a great contrast to the first generation superalloys containing about $10 \% \mathrm{Cr}$ and no Re. Similarly, $5^{\text {th }}$ generation superalloys contain osmium and ruthenium in addition to high amount of Re and very low content of $\mathrm{Cr}$. Rhenium is a unique element which can increase high temperature creep strength considerably. However, it makes the superalloys susceptible to high temperature corrosion [10]. It is due to the fact that the 
superalloys cannot form corrosion resistant alumina or chromia scale because of high Re content. Its effect is similar to Mo on oxidation i.e. as the high vapour pressure of its oxide. Therefore, rhenium is a harmful element for high temperature corrosion resistance of Ni-based superalloys. Hence, the need to apply high performance coatings for their protection under high temperature conditions as the gas turbine blades experience high temperature corrosion.

\section{Surface coating technologies}

As mentioned above, there are a number of cases reported in the literature where the gas turbine blades suffered severe corrosion due to which failures took place [1-3]. Failure investigations confirmed that it was due to hot corrosion, in which extensive penetration of sulphur took place into the superalloys leading to the formation of metal sulphides that in turn led to reduction in their mechanical properties resulting catastrophic failures. A typical failed blade is presented in fig.3. It is known that it is not possible to develop an alloy having both high temperature strength and high temperature corrosion resistance simultaneously since alloying elements often have opposing effects on the two properties. Particularly, tungsten, molybdenum and vanadium additions to superalloys are helpful in improving the high temperature strength, but their presence makes the superalloys highly susceptible to hot corrosion [7]. Therefore, it is mandatory to prevent oxidation as well as both types of hot corrosion by using appropriate coating technology [11-13] so as to increase the life of gas turbine engine components to the designed service life.

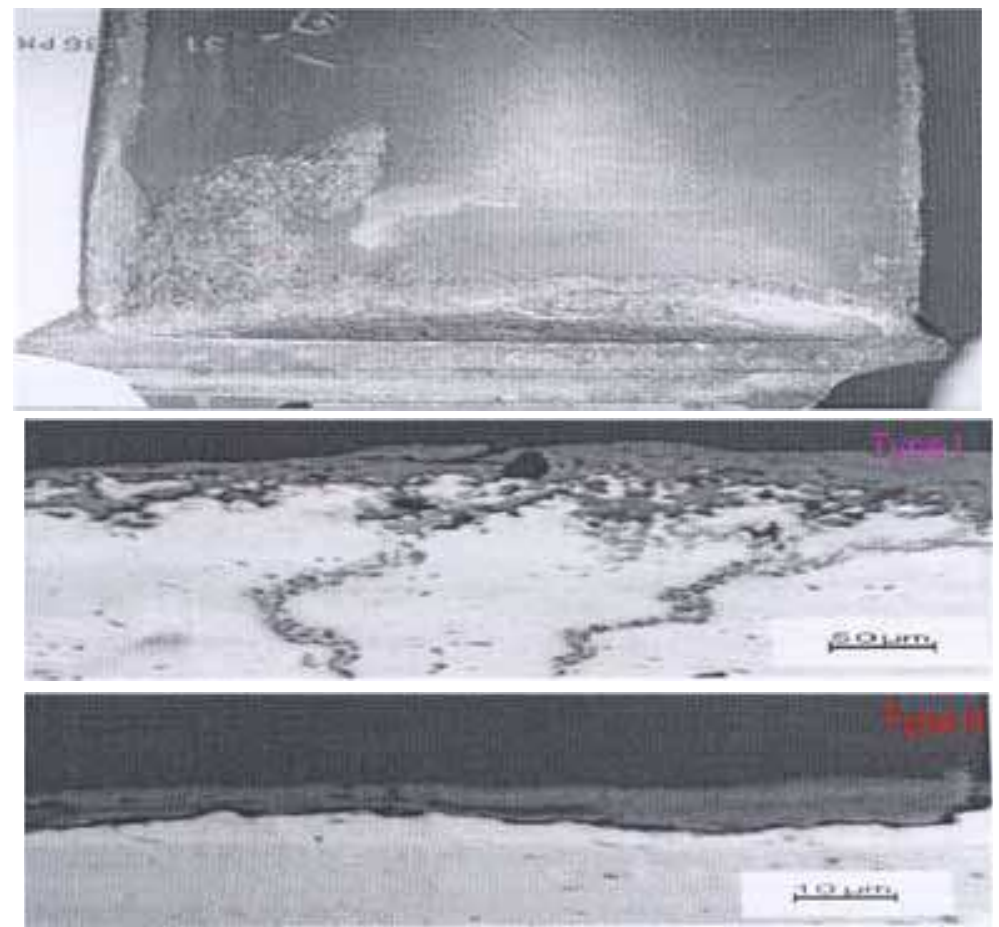

Fig. 3. Typical failed gas turbine blade due to type I and II hot corrosion 


\section{Types of coatings}

The present coatings are broadly divided into two types, diffusion and overlay. In diffusion coating application process, aluminium is made to react at the surface of substrate, forming a layer of mono-aluminide. For coatings applied over Ni-based superalloys, nickel aluminide is the resulting species. This type of coatings and surface modification is one of the most widely used for tailoring the surface properties of components. Though diffusion coatings are well bonded to the substrate they have limited compositional flexibility and their usefulness is strongly dependent on substrate chemistry. The most important improvement in the diffusion coatings has been the incorporation of platinum in aluminide coatings [14-18]. This process involves the deposition of platinum by electrochemical method followed by aluminizing at the suitable temperature for the required period. While overlay coatings are generally MCrAlY coatings where $\mathrm{M}$ is $\mathrm{Ni}$ or $\mathrm{NiCo}$ and essentially comprises a mono-aluminide component contained in a more ductile matrix of a solid solution. The supply of aluminium for formation of protective alumina scale comes largely from the dispersed mono-aluminide phase during the useful life of such coatings. Overlay coatings are typically well bonded and have a wide compositional flexibility. Research and development on this type of coatings has led to a variety of compositions with improved scale adherence [13].

It was also reported that traces of silicon as well as hafnium in MCrAlY coatings reduce the coating life drastically [13]. The underlying mechanism is that hafnium and silicon that are present in the grain boundaries of alumina scale leach out selectively by readily reacting with chlorine, vanadium, sodium and sulphur present in the corrosive environment to form corresponding compounds. This results in dislodging the grains of alumina scale and creates instability of the oxide scale and thereby reducing the life of coatings significantly. Further, the oxides of silicon and hafnium are soluble in molten basic sulphate and the basic fluxing dominates in the high temperature hot corrosion region $\left(850-950^{\circ} \mathrm{C}\right)$ [13]. The reaction mechanisms leading to reducing the life of coatings containing silicon or hafnium are given below:

$$
\begin{array}{lll}
\mathrm{HfAl}_{2} \mathrm{O}_{3}+\mathrm{Na}_{2} \mathrm{SO}_{4}+\mathrm{NaCl} & = & \mathrm{NaAlO}_{2}+\mathrm{HfCl}_{4}+\mathrm{SO}_{3} \\
\mathrm{HfAl}_{2} \mathrm{O}_{3}+\mathrm{Na}_{2} \mathrm{SO}_{4}+\mathrm{NaCl}+\mathrm{V}_{2} \mathrm{O}_{5} & = & \mathrm{NaAlVO}_{2}+\mathrm{HfCl}_{4}+\mathrm{SO}_{3} \\
\mathrm{SiAl}_{2} \mathrm{O}_{3}+\mathrm{Na}_{2} \mathrm{SO}_{4}+\mathrm{NaCl} & = & \mathrm{NaAlO}_{2}+\mathrm{Na}_{2} \mathrm{SiO}_{3}+\mathrm{SO}_{3} \\
\mathrm{SiAl}_{2} \mathrm{O}_{3}+\mathrm{Na}_{2} \mathrm{SO}_{4}+\mathrm{NaCl}+\mathrm{V}_{2} \mathrm{O}_{5}= & \mathrm{NaAlVO}_{2}+\mathrm{Na}_{2} \mathrm{SiO}_{3}+\mathrm{SO}_{3}
\end{array}
$$

Diffusion and overlay coatings can provide protection against oxidation and hot corrosion and act as bond coats for zirconia based thermal barrier coating (TBC) systems. In both the cases, slow growth rates and optimum adherence of the alumina scales formed on the coatings during high temperature exposure are of significant for component life. These requirements can be fulfilled only by using coatings with sufficiently high aluminium contents to ensure protective alumina scale formation and re-healing after oxide spallation / reaction with the environment. The life of a coating is mainly limited by aluminium depletion occurring upon aluminium consumption as a result of alumina scale growth and repeated spallation and re-healing of the alumina scale during oxidation process. If a point is reached where the aluminium level in a bond coating falls below the level at which protective alumina scale cannot be formed preferentially, faster interaction between the corrosive species present in the environment and the non-protective oxides of other 


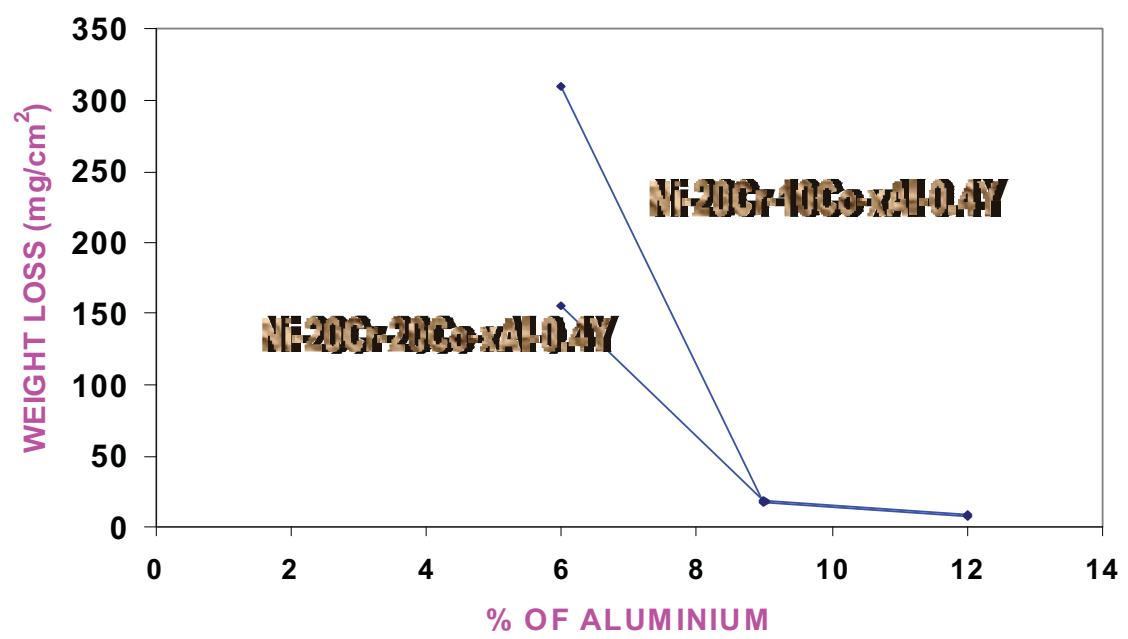

Fig. 4. Determination of optimum content of aluminium required in MCrAlY coatings for their hot corrosion resistance

constituents of the bond coating occurs and thereby affects the coating life considerably under hot corrosion conditions. Further, the constituents of ceramic thermal barrier coatings react easily with the corrosive species and shorten the coating life significantly. Therefore, optimum content of aluminium in the coatings is extremely necessary to enhance their lifetime. Fig.4 illustrates the influence of aluminium on weight loss in the MCrAlY based coating model alloys. It is very clear that aluminium plays a major role in affecting the hot corrosion resistance of MCrAlY alloys though the concentration of other alloying elements remains constant [13].

Another important aspect is the selection of suitable surface engineering technique by which the coatings are applied since the life of a coating depends not only on coating composition but also on the surface engineering technique employed for its application. Therefore, selection of appropriate surface engineering technique as well as suitable coating composition becomes a challenging task.

\section{Surface engineering techniques}

Surface engineering technique, which modifies properties of the component's surface to enhance their performance, should not only be effective but also economical. The following are the most common surface engineering techniques available at present:

a. Electro-deposition

b. Diffusion coating processes

c. Thermal spray techniques

d. Ion implantation

e. Hardening \& cladding

f. Selective surface hardening by transformation of phase and

g. vapour deposition.

Electro-deposition, diffusion and thermal spraying techniques are widely in use to improve the surface of components for hot corrosion resistance. Particularly, thermal spray and 
vapour deposition techniques are the most efficient techniques for prolonging the life of components significantly.

Researchers in the field were attempted to innovate new coating compositions by using different application techniques and concepts [19-25]. However, systematic research in simulating gas turbine engine conditions has been lacking.

\section{Smart coatings}

\subsection{Concepts}

Gas turbines used in aero engines suffer from high temperature oxidation and hot corrosion when they move across the sea. In marine and industrial gas turbines, hot corrosion is a major problem and in fact decides the life of components. Hot corrosion takes place under two temperature ranges and named type I $\left(800-950^{\circ} \mathrm{C}\right)$ and type II $\left(600-750^{\circ} \mathrm{C}\right)$. High performance coatings should combat high temperature oxidation and both forms of hot corrosion as gas turbines encounter all the problems during service. If a single coating can operate successfully over a range of temperatures with different forms of corrosion attack like type I and II hot corrosion and high temperature oxidation, the coating essentially respond to local temperature in such a way that it will form either alumina or chromia protective scale as appropriate. High purity alumina scales offer best protection against high temperature oxidation and type I hot corrosion and chromia scales against type II hot corrosion. Ideally a single coating should satisfy both the requirements. It is possible for a coating only if it contains chromium and aluminium rich graded coatings. The base coating should be a standard MCrAlY coating enriched with aluminum at its outer surface and a chromium rich layer at its inner surface. Under high temperature oxidation and type I hot corrosion conditions, the outer layer of the coating forms alumina scale, which provides protection and it, offers less protection under low temperature conditions. Under type II hot corrosion conditions, chromium rich layer forms chromia scale at a faster rate and provides protection. Thus, the smart coating can provide optimum protection by responding suitably to the temperatures that are encountered under actual service conditions of gas turbine engines. This optimum protection is possible because of the formation of most suitable protective oxide scale in each temperature range of operation envisaged. In this sense, the coating responds to its environment in a pseudo-intelligent manner and hence the name SMART COATING. With this type of coatings only, it is possible to obtain total protection for the gas turbine engines under all operating conditions which in turn possible to achieve ever greater efficiency of advanced gas turbine engines.

It is pertinent to note that the smart coating should have optimum composition with sufficient reservoir of critical elements like aluminium and chromium to form protective oxide scales depending on the surrounding temperatures. Additionally, the smart bond coating should promote slow growth rates of protective scales for enhanced service life. It helps to improve the durability of TBCs as well since TBC performance is essentially depends on the life of bond coatings [26-29] and hence necessitates compositionally optimised bond coatings. Such characteristics are possible with only MCrAlY (where M is $\mathrm{Ni}$ or $\mathrm{NiCo}$ ) type bond coatings.

Therefore, the development of smart coatings design involves the preparation of multilayered coating consisting of an appropriate MCrAlY base, enriched first in chromium, then aluminium to provide a chemically graded structure. The intermediate chromium rich phase provides protection under low temperature hot corrosion conditions; while 
aluminium rich surface layer provides resistance to high temperature oxidation and type I hot corrosion. Diffusion barrier coatings at the bottom help in preventing inter-diffusion of coating and substrate elements. Thus, the smart coating permits operation of gas turbine engines over a wide range of temperatures successfully for more than the designed life and helps in enhancing the efficiency significantly by effectively preventing oxidation, type I and type II hot corrosion [10].

\subsection{Preparation}

\subsubsection{Selection of suitable surface engineering technique}

Preparation of smart coatings is really a challenging task because the performance of coatings basically depends on it. Therefore, selection of suitable surface engineering techniques to produce a quality coating is extremely essential. Here, selection of a single technique may not be of any help, but a combination of techniques is quite useful. Further, the order of usage of selected techniques is also important. Therefore, one has to be extremely careful in selection and utilizing the techniques for production of high performance coatings in order to achieve maximum efficiency. Among the surface engineering techniques, thermal spraying, diffusion, electro-plating and laser treatments appear to be more effective in producing smart coatings. Application of suitable diffusion barrier on the superalloy followed by an optimized MCrAlY coating and chromized treatment to get $\mathrm{Cr}$ rich coating and then electroplating followed by pack cementation makes it possible to obtain graded structure as desired. Alternatively, multiple layers of optimized MCrAlY coatings rich with $\mathrm{Cr}$ and $\mathrm{Al}$ on diffusion barrier coating followed by pack cementation by using combination of surface engineering techniques makes it possible to obtain smart coatings. However, extensive research essentially helps to establish the process parameters of each surface engineering technique, coating thickness, suitable annealing treatments etc. to obtain a smart coating of desired characteristics.

The microstructures of coatings also play a significant role in enhancing the life of components. Therefore, obtaining an appropriate microstructure by identifying suitable surface engineering technique is of paramount importance. The selection of technique for coating preparation should be based on the parameters that are controllable to get required microstructure. As mentioned earlier, the smart coating is a graded coating consisting of different zones (Fig.5). Each zone has its specific microstructure with definite composition. The microstructure of each zone varies depending on the coating composition and surface engineering technique used. The composition of each zone requires detailed analysis to understand the effect of smart coating. The first layer should contain high amount of aluminium, the second layer should be rich with chromium, the third layer as that of MCrAlY coating composition and the bottom diffusion layer should contain heavy elements. Extensive research both at the laboratory and field augment to establish the appropriate coating compositions, thickness, microstructures, coating techniques and superior performance of smart coatings over conventional coatings.

\subsection{Performance of a developed smart coating}

Recently, a smart bond coating has been developed which is optimised compositionally and promotes appropriate protective scale formation depending on the surrounding environmental conditions that enhances the durability of TBC, which in turn the life of CM 247 LC superalloy components. The performances of various compositions of MCrAlY bond 


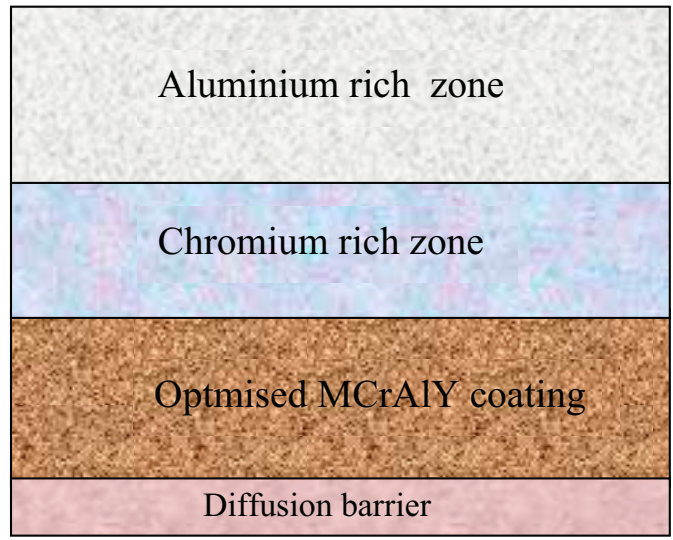

Fig. 5. A schematic representation of microstructure of a smart coating

coatings applied on CM 247 LC superalloy (without TBC) were evaluated systematically at $900^{\circ} \mathrm{C}$ in simulating gas turbine engine environments. Among the coatings, NiCoCrAlY coating exhibited a maximum life of more than 300 hours. The high performance of this coating is due to its ability to form continuous, adherent and protective alumina scale on the surface of the bond coating during high temperature corrosion at $900^{\circ} \mathrm{C}$ (Fig.6).

Table I presents the life of uncoated superalloy, smart coating as well as different thicknesses of zirconia based $\mathrm{TBCs}$ at $900^{\circ} \mathrm{C}$ in simulating gas turbine engine environments. The results indicate that $100 \mu \mathrm{m}$ thick TBC improved the superalloy life by four hundred fifty times to that of bare superalloy. It was also evident that $300 \mu \mathrm{m}$ thick TBC in association with compositionally optimised $125 \mu \mathrm{m}$ thick NiCoCrAlY bond coating (smart bond coating) enhanced the superalloy life by about 600 times, which was found to be optimum. Thick ceramic coatings could not help in improving the hot corrosion resistance of superalloys further due to adherence problem associated with spallation at higher temperatures. The maximum life of NiCoCrAlY (smart coating) $+300 \mu \mathrm{m}$ thick TBC was attributed to the formation of protective alumina and chromia scales not only on the surface of bond coating but also on the TBC surface (Fig.7 \& 8). It was observed that yttria and zirconia are still intact even after continuous exposure of 1175 hours and not reacted with the corrosive elements (Figs.7 \& 9). Further, neither sulphur nor oxygen was diffused into the coating indicating an excellent protection provided by $300 \mu \mathrm{m}$ thick TBC in association with a smart bond coating to the superalloy. It is known that TBC reduces the temperature of bond coating / substrate by about $200^{\circ} \mathrm{C}$. It indicates that the substrate or bond coating temperature is about $700^{\circ} \mathrm{C}$ only. Under such environmental conditions i.e. at $700^{\circ} \mathrm{C}$, the bond coating promoted chromia and alumina scale formation that is clearly observed in Fig.9. It was also observed that the bond coating promoted protective alumina scale formation at $900^{\circ} \mathrm{C}$ in the same environments (Fig.6). It indicates that the NiCoCrAlY bond coating forms alumina scale at $900^{\circ} \mathrm{C}$ i.e. without $\mathrm{TBC}$ and chromia and alumina scale in the presence of TBC at the same environmental conditions and provides maximum life to the TBC which in turn the superalloy components.

As already mentioned, the MCrAlY type bond coatings can provide protection against oxidation and hot corrosion and act as bond coatings for zirconia based thermal barrier coating systems. Slow growth rates and optimum adherence of protective scales forming on 


\begin{tabular}{|l|l|}
\hline Type of coating & Life (hours) \\
\hline Uncoated superalloy & $<2$ \\
\hline Smart coating & 300 \\
\hline Smart coating $+100 \mu \mathrm{m} \mathrm{TBC}$ & 910 \\
\hline Smart coating $+200 \mu \mathrm{m} \mathrm{TBC}$ & 975 \\
\hline Smart coating $+300 \mu \mathrm{m} \mathrm{TBC}$ & 1175 \\
\hline Smart coating $+400 \mu \mathrm{m} \mathrm{TBC}$ & 1170 \\
\hline
\end{tabular}

Table I. Life times of CM 247 LC alloy with smart coating + different thicknesses of thermal barrier coatings in $90 \% \mathrm{Na}_{2} \mathrm{SO}_{4}+5 \% \mathrm{NaCl}+5 \% \mathrm{~V}_{2} \mathrm{O}_{5}$ environments at $900^{\circ} \mathrm{C}$

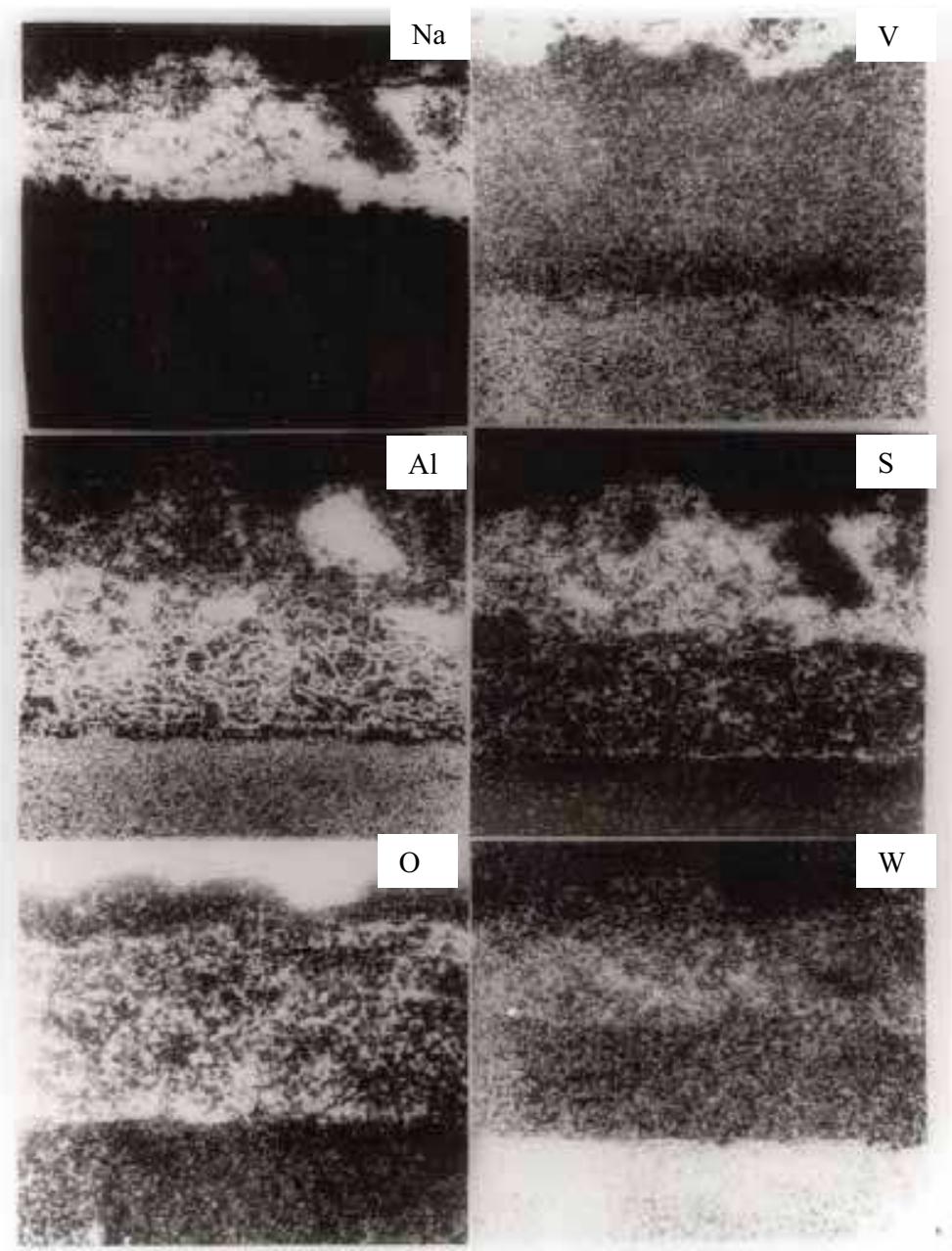

Fig. 6. Elemental distribution of $125 \mu \mathrm{m}$ thick smart coating after hot corrosion studies 

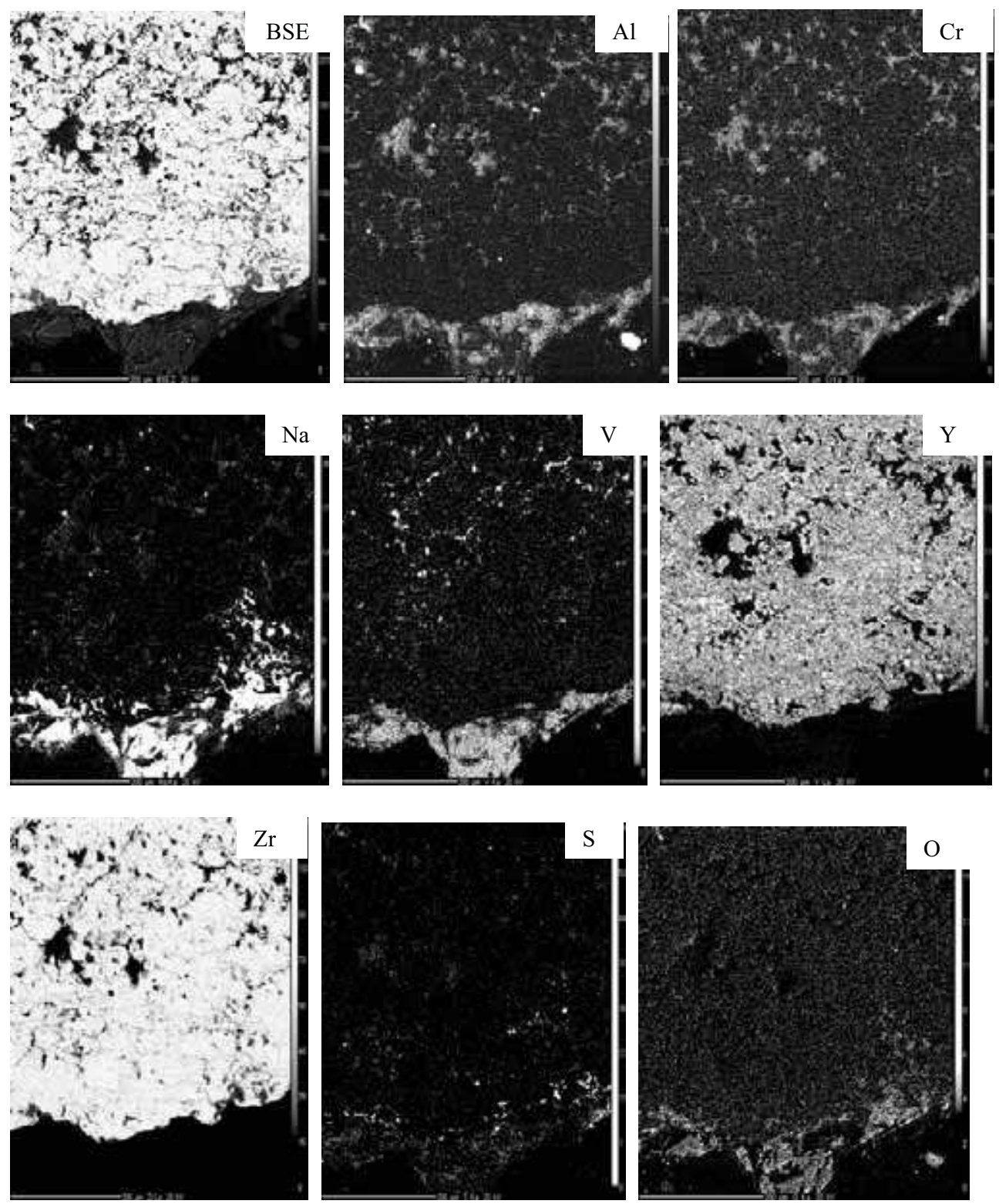

Fig. 7. Elemental distribution of $300 \mu \mathrm{m}$ thick TBC + smart coating (external layer) after hot corrosion studies 

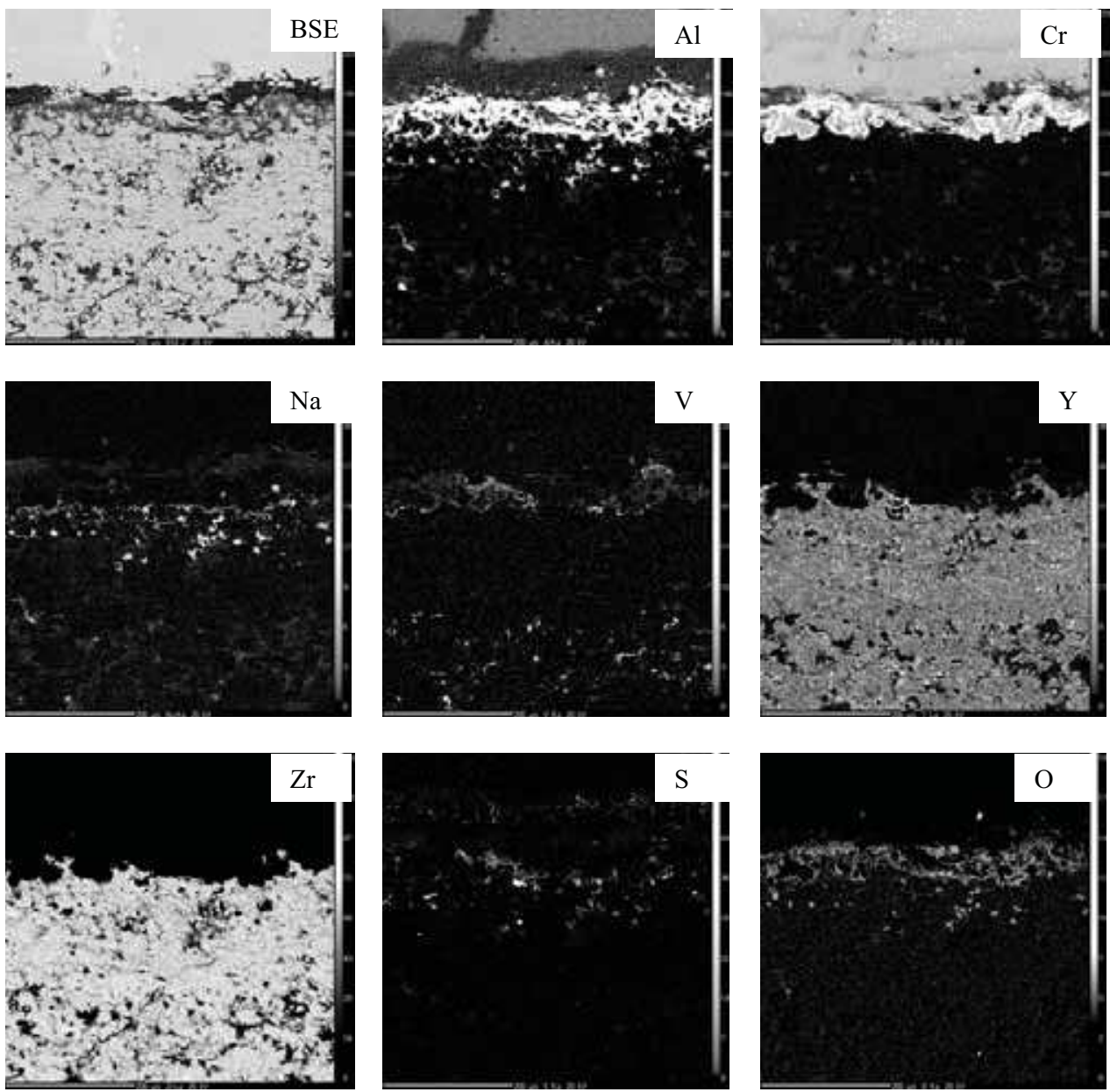

Fig. 8. Elemental distribution of $300 \mu \mathrm{m}$ thick TBC + smart coating (internal layer) after hot corrosion studies

the bond coatings during high temperature exposure are of significant for component life. These requirements can be fulfilled only by using compositionally optimised coatings with sufficiently high aluminium and chromium contents to ensure protective scale formation and re-healing after reaction with the environment. The lives of coatings are mainly limited by aluminium and chromium depletion occurring upon their consumption as a result of alumina and chromia scale growth and repeated reaction with the corrosive species. If a point is reached where the aluminium and chromium level in the bond coatings falls below the level at which protective scales cannot be formed preferentially, faster interaction between the corrosive species present in the environment by penetrating through the pores of TBC and the non-protective oxides of other constituents of the bond coating occurs and thereby affects the coatings life considerably. The performance of the smart bond coating was confirmed by employing advanced characterisation techniques. 

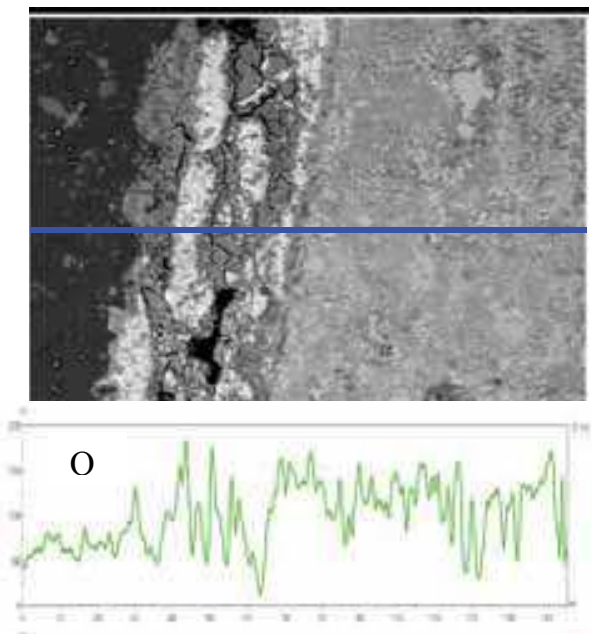

$\mathrm{Cr}$

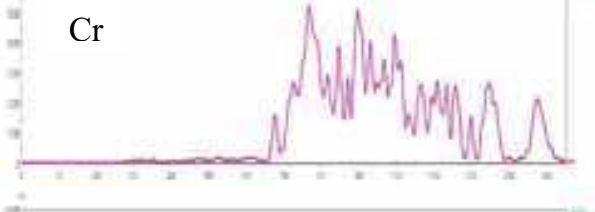

Al

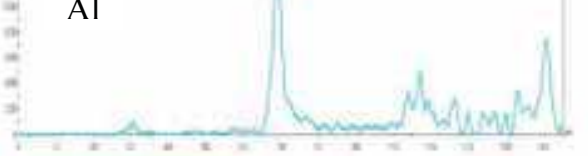

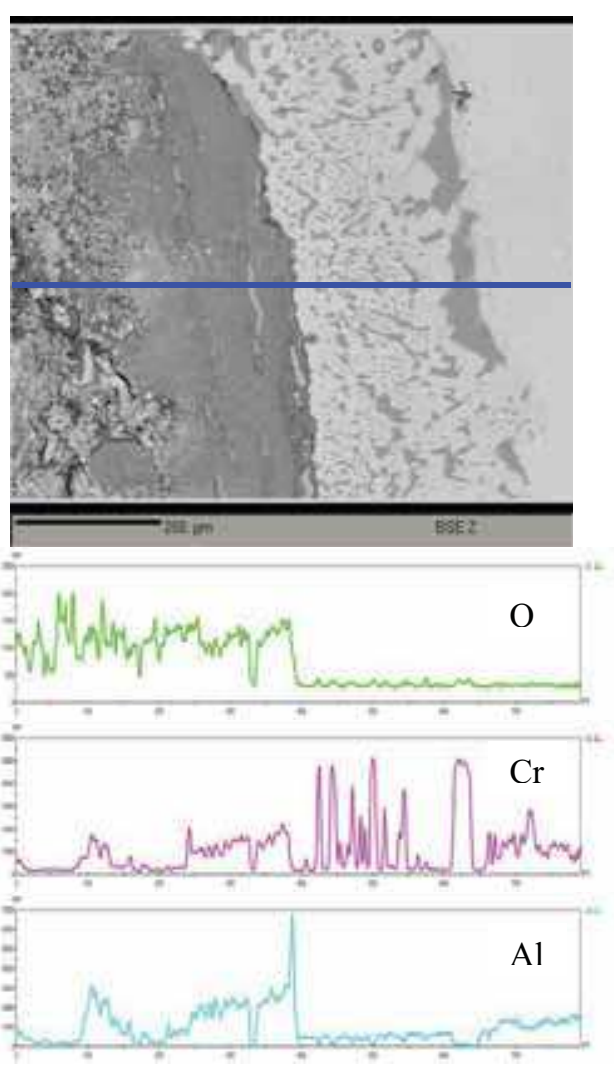

Fig. 9. Line scan data of hot corroded two layered smart coating showing alumina and chromia scale formation both on top coating surface as well as at the interface

Hence, the developed bond coating exhibited intelligence behaviour both in the presence and absence of TBC and formed suitable protective scales and hence named as smart bond coating. Another important observation is the formation of protective alumina and chromia scales on the surface of TBC as well and prevented the diffusion of corrosive elements like chlorine, vanadium, sulphur and oxygen. Thus, a smart bond coating was successfully developed for TBCs that promotes appropriate protective scales preferentially depending on the environmental conditions and enhances the life of superalloy components significantly, which is essential for advanced gas turbines for their increased efficiency. Therefore, it is a potential bond coating for advanced gas turbines of different types i.e. aero, marine and industrial for their protection against high temperature oxidation, type I and type II hot corrosion.

\section{Summary}

The design and development of smart coatings to combat type I \& type II hot corrosion and high temperature oxidation in gas turbines is a challenging problem to the Corrosion Engineer. The developmental work in this area has successfully resulted a smart coating, which provided an excellent protection to the superalloys against all the concerns that are 
being experienced by all types of gas turbines. Further research is highly essential for their understanding and to develop alternative smart coatings. Extensive research is needed both at the laboratory level and field to optimize coating composition, thickness, microstructure, identification of appropriate surface engineering techniques, and their priority of use in order to prove their performance.

\section{Acknowledgements}

The authors are grateful to the Defence Research and Development Organisation for providing financial assistance.

\section{References}

[1] M.R. Khajavi and M.H. Shariat, Engineering Failure Analysis, 11 (2004) 589

[2] J.M. Gallardo, J.A.Rodriguez and E.J. Herrera, Wear, 252 (2002) 264

[3] N. Eliaz, G. Shemesh and R.M. Latanision, Engineering Failure Analysis, 9 (2002) 31

[4] J. Stringer, Mater.Sci.Technol., 3 (1987) 482

[5] A.S.Radcliff, Mater. Sci. \& Tech., 3 (1987) 554

[6] R.F.Singer, Mater. Sci. \& Tech., 3 (1987) 726

[7] I.Gurrappa, Oxid. Met., 50 (1999) 353

[8] I.Gurrappa, J.High Temp.Mater.Sci., 38 (1997) 137

[9] I.Gurrappa, Mater.Sci.Technol., 19 (2003) 178

[10] I.Gurrappa, 'Design and Development of smart Coatings for Aerospace applications', Final Project Report, European Commission, July 2008

[11] H.W. Grunling, H. Rechtanbacher and L. Singheiser, Mater. Sci. Forum, 251-254 (1997) 483

[12] S.Kuroda, J.Kawakita, M. Watanabe and H. Katamoda, Sci. Tech. Adv. Mater., 9 (2008) 33002

[13] I.Gurrappa, I.V.S.Yashwanth, A.K.Gogia, H.Murakami and S.Kuroda, Intl. Mater. Rev., (Submitted)

[14] I.Gurrappa, Platinum Met.Rev., 45 (2001) 124

[15] I.Gurrappa and A.K.Gogia, Mater. Sci. Technol., 17 (2001) 581

[16] I.Gurrappa, Surf.Coat.Technol., 139 (2001) 216

[17] K.T.Chiang, F.S.Pettit and G.H.Meier, High Temperature Corrosion (ed.) R.A.Rapp, NACE, Houston, Texas, (1981) p 519

[18] G.Lehnert and H.Meinhardt; Electrodep. Surf. Treat., 1 (1972) 171

[19] M.P.Bacos, P. Josso, N.Vialas, D. Poquillon, B.Pieraggi, D.Monceau, J.R.Nicholls, N. Simms, A.Encinas-Oropesa, T.Ericsson and S.Stekovic, Appl.Thermal.Eng., 24 (2004) 1745

[20] F.Wu, H. Murakami, A. Suzuki and H. Harada, Surf. Coat. Tech., 168 (2003) 62-69

[21] P. Kuppusami, H. Murakami and T. Ohnuma, J. Vac. Sci. Tech., A22 (2004) 1208

[22] C.E.Campbell, W.J.Boettinger, U.R.Kattner, Acta Mater., 50 (2002) 775

[23] L.Lee, D.Windover, M.Audino, D.W.Matson, E.D.MacClanahan, Surf. Coat.Techonol., 149 (2002) 62

[24] Y.N. Wu, A. Yamaguchi, H.Murakami and S. Kuroda, J. Mater. Res., 22 (2007) 206

[25] K. Kawagishi, A. Sato and H. Harada, JOM (2008) 31 (www.tms.org/jom.html)

[26] I.Gurrappa, Proceedings of International convention on Surface Engineering (INCOSURF 2004), August 2004, Bangalore, India, p 115

[27] M.Y.Ali, S.Q-Nusier and G.M.Newaz, Intl. J. Solid Struct., 38 (2001) 3329

[28] D.R. Mumm and A.G.Evans, Durable Surf., 197 (2001) 199

[29] R.Vassen, G.Kerkhof and D.Stover, Mater. Sci. Eng., A 303 (2001) 100 


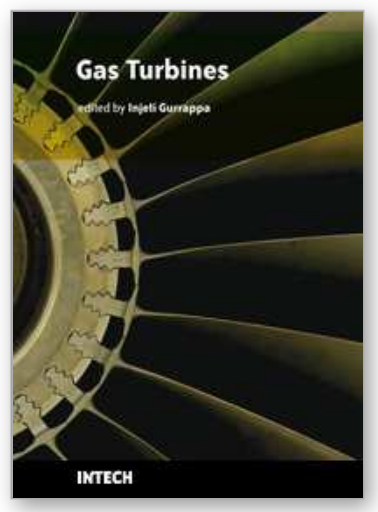

\author{
Gas Turbines \\ Edited by Gurrappa Injeti
}

ISBN 978-953-307-146-6

Hard cover, 364 pages

Publisher Sciyo

Published online 27, September, 2010

Published in print edition September, 2010

This book is intended to provide valuable information for the analysis and design of various gas turbine engines for different applications. The target audience for this book is design, maintenance, materials, aerospace and mechanical engineers. The design and maintenance engineers in the gas turbine and aircraft industry will benefit immensely from the integration and system discussions in the book. The chapters are of high relevance and interest to manufacturers, researchers and academicians as well.

\title{
How to reference
}

In order to correctly reference this scholarly work, feel free to copy and paste the following:

I. Gurrappa and I.V.S Yashwanth (2010). Design and Development of Smartcoatings for Gas Turbines, Gas Turbines, Gurrappa Injeti (Ed.), ISBN: 978-953-307-146-6, InTech, Available from: http://www.intechopen.com/books/gas-turbines/design-and-development-of-smart-coatings-for-gas-turbines

\section{INTECH}

open science | open minds

\author{
InTech Europe \\ University Campus STeP Ri \\ Slavka Krautzeka 83/A \\ 51000 Rijeka, Croatia \\ Phone: +385 (51) 770447 \\ Fax: +385 (51) 686166 \\ www.intechopen.com
}

\author{
InTech China \\ Unit 405, Office Block, Hotel Equatorial Shanghai \\ No.65, Yan An Road (West), Shanghai, 200040, China \\ 中国上海市延安西路 65 号上海国际贵都大饭店办公楼 405 单元 \\ Phone: +86-21-62489820 \\ Fax: +86-21-62489821
}


(C) 2010 The Author(s). Licensee IntechOpen. This chapter is distributed under the terms of the Creative Commons Attribution-NonCommercialShareAlike-3.0 License, which permits use, distribution and reproduction for non-commercial purposes, provided the original is properly cited and derivative works building on this content are distributed under the same license. 